\title{
Psychoendocrine Validation of a Short Measure for Assessment of Perceived Stress Management Skills in Different Non-Clinical Populations
}

\author{
Running title: ISBF validation
}

\footnotetext{
${ }^{\text {*a,b }}$ Petra H. Wirtz, Ph.D., ${ }^{\mathrm{a}}$ Livia Thomas, M.S., ${ }^{\mathrm{c}}$ Gregor Domes, Ph.D., ${ }^{\mathrm{d}}$ Frank J. Penedo, Ph.D., ${ }^{\mathrm{b}}$ Ulrike Ehlert, Ph.D. \& ${ }^{\mathrm{e}}$ Fridtjof W. Nussbeck, Ph.D.

${ }^{a}$ Biological and Health Psychology, University of Bern, Switzerland

${ }^{\mathrm{b}}$ Department of Clinical Psychology and Psychotherapy, University of Zurich, Switzerland

${ }^{c}$ Department of Psychology, University of Freiburg, Germany

${ }^{\mathrm{d}}$ Department of Psychology and Psychiatry \& Behavioural Sciences, University of Miami, U.S.A.

${ }^{\text {e }}$ Department of Clinical Psychology with focus on children/adolescents and families/couples, University of Zurich, Switzerland
}

*Address for correspondence and reprint requests:

Petra H. Wirtz, Ph.D.

University of Bern

Department of Psychology

Biological and Health Psychology

Alpeneggstrasse 22

3012 Bern

Switzerland

Tel.: +41 31631 5790, Fax: +41 316314155

Email: petra.wirtz@psy.unibe.ch 


\begin{abstract}
Background: We investigated the psychometric properties of a short questionnaire for combined assessment of different perceived stress management skills in the general population and tested whether scores relate to physiological stress reactivity.

Methods: For psychometric evaluation, we determined the factor structure of the questionnaire and investigated its measurement invariance in the participant groups and over time in three different independent samples representing the general population (total $\mathrm{N}=332$ ). Reliability was tested by estimating test-retest reliability, internal consistency, and item reliabilities. We examined convergent and criterion validity using selected criterion variables. For endocrine validation, 35 healthy non-smoking and medication-free men in a laboratory study and 35 male and female employees in a workplace study underwent an acute standardized psychosocial stress task. We assessed stress management skills and measured salivary cortisol before and several times up to 60min (workplace study) and 120min (laboratory study) after stress. Potential confounders were controlled.

Results: The factor structure of the questionnaire consists of five scales reflecting acceptably distinct stress management skills such as cognitive strategies, use of social support, relaxation strategies, anger regulation, and perception of bodily tension. This factor structure was stable across participant groups and over time. Internal consistencies, item reliabilities, and test-retest reliabilities met established statistical requirements. Convergent and criterion validity were also established. In both endocrine validation studies, higher stress management skills were independently associated with lower cortisol stress reactivity (p’s<.029).
\end{abstract}

Conclusions: Our findings suggest that the questionnaire has good psychometric properties and that it relates to subjective psychological and objective physiological stress indicators. Therefore, the instrument seems a suitable measure for differential assessment of stress management skills in the general population. 
Key words: stress management skills, validation, questionnaire, cortisol, TSST 


\section{INTRODUCTION}

Accumulating evidence suggests adverse health effects of psychosocial stress, particularly if strenuous and repeated. In particular, large-magnitude physiological reactions to acute stressors have been implicated with poor health outcomes across several health conditions and particularly in cardiovascular disease (Holmes et al., 2006; Brotman et al., 2007; Chida and Steptoe, 2010).

Physiological stress reactivity has been shown to relate to psychological factors. An important identified psychological determinant of physiological stress reactivity is the cognitive appraisal of the stressful situation as proposed by Lazarus and Folkman (Lazarus and Folkman, 1984; Gaab et al., 2005). According to these investigators, the overall stress appraisal results from two cognitive appraisal processes, namely primary and secondary stress appraisals. While an individual's primary stress appraisal comprises perceived threat and challenge of a given stressful situation, secondary appraisal involves an evaluation of "what might and can be done” (Lazarus and Folkman, 1984) and reflects the individual's resources to master the stressful situation. Our group previously found that anticipatory cognitive stress appraisal determines the extent of an individual's hypothalamus pituitary adrenal (HPA)-axis reactivity to a potent standardized psychosocial stressor (Gaab et al., 2005). In contrast, social support has been suggested to maintain or even improve health by reducing psychobiological reactivity to stressors (Lepore, 1998; Christenfeld and Gerin, 2000). Indeed, various findings suggest that social support attenuates a variety of psychological and physiological stress responses (Seeman and McEwen, 1996; Uchino et al., 1996; Christenfeld and Gerin, 2000; Heinrichs et al., 2003; Uchino, 2006; Wirtz et al., 2006; Nausheen et al., 2007; Wirtz et al., 2009), whereas loneliness or social inhibition are associated with heightened psychobiological stress responses (Habra et al., 2003; Nausheen et al., 2007). Furthermore, poor anger regulation as indicated by higher aggression, hostility, or outwardly negatively expressed anger (anger-out) has been associated with heightened physiological reactivity to 
mental stress, particularly of the cardiovascular system (Chida and Hamer, 2008). These examples suggest that psychological and physiological stress responses may depend on the extent to which an individual can engage in several processes known to modulate the effects of stress.

Consequently, many current stress management interventions aim at training stress management skills by modulating psychological determinants and correlates of physiological stress reactivity. Typical stress management techniques include providing cognitive strategies such as cognitive restructuring, self-instructions, and systematic problem solving (Meichenbaum, 1985, 1991; Kaluza, 1996; Siegrist, 1998; Wagner-Link, 2001; Gaab et al., 2003; Hammerfald et al., 2005) intended to modulate the cognitive stress appraisal processes to allow for optimal coping with a given stressful situation. Indeed, training individuals with cognitive strategies reduced anticipatory cognitive stress appraisal of a standardized stress situation which in turn predicted lower HPA axis responses to a standardized psychosocial stressor (Gaab et al., 2003; Hammerfald et al., 2005). Additional components of current stress management interventions include training of social skills (Reschke, 2000; Wagner-Link, 2001; Hinsch and Pfingsten, 2007), or anger regulation skills (Siegrist, 1998; Wiegard, 2000). The former aims at improving a person's potential to successfully initiate and maintain social contacts and thus increase perceived and given social support. The latter usually aims at reducing feelings of anger and uncontrolled outward anger expression either by cognitive restructuring (in unchangeable situations) or by assertive behaviour (in changeable situations). Relaxation techniques such as progressive muscle relaxation have been shown to acutely decrease activity of stress-responsive systems and thus possibly prepare for either active stress management or regeneration (Cruess et al., 2000; Pawlow and Jones, 2002, 2005). Moreover, awareness of bodily tension is often integrated in stress management interventions (Meichenbaum, 1985, 1991; Gaab et al., 2003; Hammerfald et al., 2005). This component is likely to function as an indicator of the current stress level that does not per se 
reduce perceived stress but most likely serves as a cue to stimulate the active use of other stress management techniques by creating awareness of adverse effects of stress such as bodily tension.

Despite a number of studies documenting the psychological and physiological adverse effects of stress, and the role that several psychosocial processes (e.g., cognitive restructuring, emotional expression, ability to relax) may play in modulating such negative effects, there is no published standardized single instrument for assessment of stress management skills in the general population. Any such instrument should optimally be reliable, valid, and short. The only hitherto existing instrument whose items address relevant stress management skills is the “Measure of Current Status” (MOCS), a 17-item questionnaire in English language by Charles Carver that has been developed for use in cancer patients (Carver, 2005). This scale showed adequate factor structure and internal consistency in samples of cancer patients and thus provided promising results (Penedo et al., 2003; Penedo et al., 2004; Antoni et al., 2006; Penedo et al., 2006). However, psychometric qualities of the instrument in non-cancer and non-clinical samples that more likely represent the general population have not yet been investigated.

Here, we investigate the psychometric properties of a short questionnaire based on the items of the MOCS in three different independent samples of non-patient populations in Germany and Switzerland. We determined the factor structure, measurement invariance across different participant groups and over time, test-retest reliability, internal consistency, item reliabilities, as well as convergent and criterion validities. Furthermore, we investigated associations between stress management skills and reactivity of the HPA axis as a major human neuroendocrine stress system in reaction to a potent psychosocial stress test that combines both uncontrollable and social-evaluative elements. We measured salivary cortisol levels before and several times after stress in a laboratory study and in a workplace study while controlling for known confounders. 
In terms of criterion validity, we hypothesized that higher social skills would be reflected by higher levels of perceived social support while successful anger regulation would relate to lower outward anger expression and higher anger control. We expected that cognitive strategies lower subjective stress reactivity and levels of perceived cognitive and emotional strain in daily life and that they influence a person's coping style in terms of higher task and lower emotion orientation. In addition, we hypothesized that higher relaxation abilities and lower bodily tension relate to lower stress reactivity and lower feelings of exhaustion as exhaustion is supposed to result from prolonged stress experience (Appels, 1997). In terms of neuroendocrine validity, we hypothesized that higher stress management skills would be associated with lower cortisol stress reactivity.

\section{METHODS}

\section{Study participants and procedure}

\section{Psychometric Validation}

The total sample for the psychometric validation $(N=332)$ consisted of three different subsamples. Sample 1 ("general sample”, $N=89$ ) was recruited from the general population of the German part of Switzerland by word-of-mouth referrals during 2.5 months. Sample 2 ("student sample”, $N=127$ ) was a student sample recruited in the Department of Psychology at the University of Zurich, Switzerland at the end of the autumn semester of 2009. Sample 3 (“employee sample”, $N=116$ ) was recruited from employees of a German health insurance company who were willing to participate in the study. Samples 1 and 2 were assessed in 2009 while sample 3 was assessed during 2004 and 2005.

We recruited men and women between 18 and 80 years of age who were native German speakers. No exclusion criteria other than age were applied. The total sample had a mean age of 31 years \pm 10.61 (SD) (mean $\pm S D$; sample 1: $37 \pm 14.15$; sample 2: $25 \pm 5.91$; sample 3: 32 \pm 8.02 ). About 19.3\% were men (sample 1:37.1\%; sample 2:11.8\%; sample 
3:14.76\%) and 69.3\% were women (sample 1:61.8\%; sample 2:86.6\%; sample 3:56.6\%) while $10.1 \%$ of participants did not indicate their gender (sample 1:1.1\%; sample 2:1.6\%; sample 3:26.7\%).

All participants were asked to complete the ISBF questionnaire twice either with or without additional assessment of the five validation questionnaires (see Supplemental Material 1). The retest interval of samples 1 and 2 was 7-14 days (mean \pm SEM:8.5 \pm 1.93 ). Sample 3 received the second set of questionnaires 10 weeks after completing the first set and was instructed to complete this second set within one week. The study was carried out in accordance with the Declaration of Helsinki principles.

\section{Endocrine Validation}

Study participants. For endocrine validation purposes we recruited a total of 70 participants who were investigated either in a laboratory setting (laboratory study) or in a workplace setting (workplace study). Subject characteristics are provided in Table 4.

The laboratory study comprised 35 medication-free, non-smoking men aged 20-62 years who were in excellent physical and mental health, as confirmed by an extensive health questionnaire and telephone interview. Recruitment was carried out during blood donation events of the Swiss Red Cross of the State of Zurich, by word-of-mouth referrals, and by advertisements on university webpages. The study was conducted from Dec 2009 to Jan 2011. The Ethics Committee of the State of Zurich, Switzerland, formally approved the research protocol. Additional details are described in Supplemental Material 2.

In the workplace study, we recruited 35 male and female employees of the same German health insurance company as described in the psychometric validation part who were available at the test days in the office buildings were stress tests were performed (see below). The study was conducted in August and October 2004, and July 2005. The company’s board of management and staff council formally approved the research protocol. 
Procedure. Laboratory study: Upon arriving to the laboratory of the University of Zurich, participants were seated in a comfortable chair in a quiet room and were provided a standardized meal (jelly sandwich, 50g of flavanol-free chocolate), followed by a 2-hour rest period during which the ISBF questionnaire (see below) was administered (at about 13:00h) and completed. At 14:00h participants performed the Trier Social Stress Test (TSST) (see below). After the task, subjects remained seated for a 120-min recovery period. Saliva samples were taken one minute before subjects were introduced to the TSST as well as immediately thereafter, and 10, 20, 30, 45, 60, 90, and 120 minutes after completion of the TSST. Participants received 175 Swiss Francs compensation. Mean arterial blood pressure (MAP, 1/3 systolic blood pressure (SBP) + 2/3 diastolic blood pressure (DBP)) (Schmidt and Thews, 1987) was assessed as the mean of two BP readings by Omron sphygmomanometry (Omron 773, Omron Healthcare Europe B.V. Hoofddorp, The Netherlands) obtained during the waiting period prior to TSST begin.

Workplace study: The testing sessions of the workplace study were performed on 4 days in the company’s office buildings in Russelsheim (2 test days), Hallbergmoos (1 test day), and Offenbach (1 test day) (all Germany). All TSST sessions commenced at 13:00h with inter-subject start intervals of 30 minutes, i.e. the next subject started 30 min later at 13:30h. Participants were seated in a quiet room for $30 \mathrm{~min}$ and completed the ISBF questionnaire before performing the TSST. After TSST cessation subjects remained seated for another $60 \mathrm{~min}$. Samples of saliva were taken one minute before subjects were introduced to the TSST as well as immediately thereafter, and 10, 20, 30, 45, and 60 minutes after completion of the TSST.

\section{Assessment of Stress Management Skills}

We used a 14-item questionnaire to assess perceived stress management skills (“Inventar zur Erfassung von Stressbewältigungsfertigkeiten” (English translation: 
inventory for assessment of stress management skills), ISBF (see Table 1)). The ISBF questionnaire is based on the 17 items of the Measure of Current Status (MOCS), a questionnaire in English language (Carver, 2005) that has been developed and used to test the effectiveness of stress management trainings in cancer patients (Penedo et al., 2003; Penedo et al., 2004; Antoni et al., 2006; Penedo et al., 2006). The MOCS was designed to assess perceived management skills (i.e., the perceived ability to respond to the challenges and demands of everyday life). The items of the MOCS are based on the components of most cognitive behavioral stress management interventions such as cognitive strategies and problem solving, use of social support, awareness of tension, anger management, and relaxation. The measure asks participants to rate on a 5-point response scale how well they can perform each of the 17 items (i.e. "I cannot do this at all” to "I can do this extremely well”). Hitherto, psychometric properties of the MOCS have only been investigated in cancer patients with either prostate cancer (Penedo et al., 2003; Penedo et al., 2004; Penedo et al., 2006) or breast cancer (Antoni et al., 2006). In these samples, the factor structure and internal consistency of the MOCS have been tested but results differ (for details see Supplemental Material 3). First assessment of criterion validity in a subsample $(N=46)$ of the prostate cancer population suggests greater optimism and positive mood were positively and significantly correlated with higher MOCS total scores (Penedo et al., 2003). However, the psychometric validation of the questionnaire remains lacking as study samples only comprised cancer patients. Furthermore, no test of measurement invariance across groups, or of the stability of the factor structure over time, or information about test-retest reliability were provided and convergent and criterion validity using additional adequate validation measures have not been examined so far.

We translated the 17 items of the MOCS into German language and used this item pool as the basis for our psychometric validation study of the ISBF questionnaire. Based on the contents of this item pool representing the previously mentioned stress management 
components, we expected a five-factor solution as depicted in Table 1 to represent the internal structure of the ISBF.

\section{Validation instruments}

Stress reactivity. Subjective stress reactivity was measured using the StressReactivity-Scale (SRS) (P. Schulz et al., 2005). The SRS assesses the experience of typical emotional and bodily reactions to different types of stress situations.

Irritation. The Irritation scale describes subjective perceived emotional and cognitive strain in occupational contexts (A. Müller et al., 2004; Mohr et al., 2005) and includes both, ruminations in terms of reinforced goal-orientation (cognitive irritation), and irritability in terms of goal defence (emotional irritation).

Social support. Perceived social support (PSS) was assessed by the 8-item subscale of the Berlin Social Support Scale (BSSS) (U. Schulz and Schwarzer, 2003).

Anger. We used the German version of the Spielberger State-Trait Anger Expression Inventory (STAXI) (Schwenkmezger et al., 1992; C. Müller et al., 2001) and assessed the subscales “anger-out” and “anger control” for validation purposes. Anger-out describes the extent to which a person expresses his or her emotional experience of anger in an outwardly negative or poorly controlled manner. This may involve expression of hostile or aggressive actions, or verbal expression of angry emotions. Anger-control refers to the tendency to engage in behaviors intended to reduce overt anger expression.

Vital Exhaustion. Vital exhaustion (VE) is a psychological state characterized by mental fatigue, increased irritability, and demoralization. VE was assessed by the German version of the nine item short form of the Maastricht Exhaustion Questionnaire (Kopp et al., 1998; Wirtz et al., 2003; Kudielka et al., 2004b). In detail, the nine items ask about undue tiredness, troubles falling asleep, repeated waking up at night, general malaise, listlessness, irritability, loss of energy, demoralization, and waking up exhausted. 
Coping. Different coping styles were examined using the German short form of the “Coping Inventory for Stressful Situations” (CISS, (Endler and Parker, 1990; Kälin, 1995)). For the purpose of ISBF validation we used the subscales assessing task-oriented and emotion-oriented coping styles.

All validation instruments are described in more detail in Supplemental Material 4.

\section{Psychosocial Stress Test (Endocrine Validation)}

To inflict acute psychosocial stress, we used the well-standardized Trier Social Stress Test (TSST) comprising 5 min of preparation, a mock job interview (5 minutes), and mental arithmetic (serial subtraction, 5 minutes) in front of an unknown panel of two persons in white coats (Kirschbaum et al., 1993). The TSST has repeatedly been found to induce profound physiological responses (Kirschbaum et al., 1993; Dickerson and Kemeny, 2004).

\section{Biochemical Analyses (Endocrine Validation)}

For assessment of salivary free cortisol levels, saliva was collected by subjects using Salivette collection devices (Sarstedt, Rommelsdorf, Germany) and stored at $-20^{\circ} \mathrm{C}$ until biochemical analysis. Saliva samples were thawed and spun at $3000 \mathrm{rpm}$ for 10 minutes yielding low-viscosity saliva. Cortisol concentrations were measured using a commercially available competitive chemiluminiscence immunoassay with high sensitivity of $0.16 \mathrm{ng} / \mathrm{ml}$ (LIA, IBL Hamburg). Intra- and interassay variability were $<7.7$ and $11.5 \%$, respectively.

\section{Statistical Analyses}

Psychometric properties of the ISBF were analyzed as follows:

Factor structure and reliability. To determine the number of facets (sub-scales) that are inherent in the ISBF we conducted an Exploratory Factor Analysis (EFA) using the 
"general sample” (sample 1). The results of this EFA were then used in a Confirmatory Factor Analytic (CFA) approach to investigate if the factor structure found in the first analysis could be replicated in all three participant samples (samples 1 to 3). Additionally, we checked if the model parameters remain identical over sub-populations using a multiplegroup approach (measurement invariance over groups). Furthermore, we tested the stability of the factor structure over time by extending the multiple-group analysis to repeated measures. Finally, reliability coefficients were estimated (scale reliability: internal consistency = Cronbach's $\alpha$; retest reliability: test-retest correlations; item reliability: variance of the item explained by the scale). Cronbach's $\alpha$ and test-retest correlations were computed using SPSS software packages (SPSS, Chicago, IL). Item reliabilities were obtained as a result of the factor analytic analyses which were carried out with Mplus 6 (Muthén and Muthén, 19982010) using the robust full-information maximum-likelihood (FIML-R) estimator. This estimator uses all available information in the data sets. Therefore, sample sizes may vary slightly from analysis to analysis depending if subjects provide information on any of the scores. The goodness of fit of the different models was examined relying on the $\chi^{2}$ values, the TLI, and on the Root Mean Square Errors of Approximation (RMSEA). Following established guidelines, tests for model fit were determined as follows: non-signifcant $p$ values of the $\chi^{2}$ values; TLI $>.97$ and RMSEA $<.05$ indicate good model fit; a ratio of $\chi^{2}$ to degrees of freedom $<3$, TLI $>.95$, and RMSEA $<10$ indicate acceptable fit (SchermellehEngel et al., 2003).

Validity. Correlations of the different subscales were estimated in order to depict the convergent validity of the total scale. Additionally, the criterion validity of the ISBF was examined: We compared the predictive power of the total scale, the set of sub-scales, and the particularly matching subscales with respect to the selected criterion variables (i.e., general stress reactivity, irritation, perceived social support, anger-out, anger control, vital exhaustion, as well as task- and emotion-oriented coping styles). The criterion variables 
served as dependent variables in multiple regression analyses. We evaluated regression models by the amount of explained variances but additionally considered the $p$-values associated with different regression coefficients. Correlation and regression analyses were carried out using SPSS.

For endocrine validation, statistical analyses were performed as follows: all calculations were performed using SPSS. Data are presented as mean \pm SEM. Results were considered statistically significant at the $\mathrm{p} \leq .05$ level and all tests were two-tailed. Continuous data were tested for normal distribution and homogeneity of variance using a KolmogorovSmirnov and a Levene’s test before statistical procedures were applied. For assessment of associations between stress management skills and cortisol stress reactivity, we calculated general linear models (GLM) with repeated measures of cortisol as dependent variables and ISBF total score as continuous independent variable following previous methods while controlling for potential confounders as covariates (Wirtz et al., 2009). To avoid overcontrolling given our sample sizes we restricted the number of covariates (Babyak, 2004). In the laboratory study we controlled for age, BMI, and MAP as covariates to rule out a potential confounding influence of these parameters (Kudielka et al., 2004a; Wirtz et al., 2006). In the workplace study we controlled in a first step for three known strong confounders of cortisol stress reactivity, i.e. hormonal contraceptive intake, gender, and age (Kirschbaum et al., 1999; Kudielka et al., 2004a). In a second step, we then additionally controlled for BMI and smoking (number of smoked cigarettes per day). MAP was not measured in that study and was thus not controlled. For assessment of associations between ISBF total scores and cortisol at rest, we calculated linear regression analyses controlling for the same sets of confounders as described above. We used stress ISBF total scores as continuous variables in all analyses to avoid artificial dichotomization which would result into a loss of statistical power. In additional complementary analyses, we combined data of both studies and repeat analyses with cortisol data from before stress to $60 \mathrm{~min}$ after stress 
cessation while controlling for age, BMI, hormonal contraceptive intake, gender, and smoking, and a variable coding the study (laboratory study vs. workplace study). Although not employed for modeling and testing, for illustrative purposes we categorized the study subjects into quartiles based on their ISBF total scores.

\section{RESULTS}

\section{PSYCHOMETRIC VALIDATION STUDY}

\section{Factor structure}

Factor structure. The EFA for the general sample revealed that the questionnaire fairly reflects the five theoretically postulated sub-dimensions depicted in Table 1 ( $\chi^{2}$ (scaled) $=101.13 ; d f=61 ; p=.00 ;$ TLI = .61; RMSEA = .09). However, items 3, 6, and 11 (Table 1) did not load substantively (all loadings $<.31$ ) on any of the five factors. Therefore, we ran all remaining analyses without items 3, 6, and 11 . The CFA-model for sample 1 showed an acceptable fit to the data $\left(\chi^{2}(\right.$ scaled $)=116.24 ; d f=71 ; p=.00 ;$ TLI $=.86$; RMSEA $\left.=.09\right)$, except for the TLI score. The cross validations using samples 2 and 3 showed comparable goodness-of-fit coefficients $\left(\right.$ sample $2: \chi^{2}($ scaled $)=115.29 ; d f=70 ; p=.00 ;$ TLI $=.88$; RMSEA $=.07$; sample $3: \chi^{2}($ scaled $)=121.57 ; d f=70 ; p=.00 ;$ TLI $=.88 ;$ RMSEA $\left.=.08\right)$.

Stability of the factor structure over groups. The multi-group CFA model showed that a model with identical factor loadings, intercepts, residual variances, latent variances and covariances across groups fits well $\left(\chi^{2}\right.$ (scaled) $=544.37 ; d f=294 ; p=.00 ; \chi^{2} / d f<2$; TLI $=$ .84 ; RMSEA $=.09$ ), again except for the TLI. Table 1 presents the model parameters of the multiple-group CFA. In this model, measurement invariance (Meredith, 1993) holds.

Please insert Table 1 around here 
Stability of the factor structure over time. In order to test measurement invariance over groups and time, we estimated a longitudinal multigroup-CFA model. We restricted the loading parameters and error variances to be invariant across groups and time. Additionally, the factor variances and correlations as well as the intercepts were restricted to be identical across samples within time points. However, this resulted in an overfactorized model since there were perfect correlations over time in samples 1 and 2 for almost all factors (perfect test-retest reliabilities). Therefore, we respecified the model using only one factor over time (with identical loading parameters) representing perfect stability of the factors over time for samples 1 and 2. For sample 3, we specified two factors for each construct over time. The model fits fairly well to the data $\left(\chi^{2}(\right.$ scaled $)=2594.88 ; d f=1110 ; p=.00 ; \chi^{2} / d f<2.5 ;$ TLI $=$ .69 ; RMSEA = .11). The model parameters virtually did not change from the cross-sectional to the longitudinal application. Therefore, we will not represent the model parameters again.

\section{Reliability}

Reliability coefficients (considering all samples) are depicted in Table 1 (last column). Internal consistencies are high for all scales except for relaxation abilities (all $\alpha$ 's $>$ .70). For that scale internal consistency is still acceptable $(\alpha>.67)$ considering that only two items are used to assess this subscale. Item reliabilities are indicated by the amount of explained observed variance of the items and have been found to be satisfyingly high. According to the longitudinal multigroup CFA model, we found perfect test-retest reliabilities $\left(R^{2}=1.00\right)$ for samples 1 and 2 (with a retest interval of only 7 to 14 days). For sample 3 (test-retest interval of 10 weeks), we found retest reliabilites as depicted in Table 2. Three of the five scales ("cognitive strategies and problem solving”, "identification and use of social resources”, and “relaxation abilities”) show very high test-retest reliabilities whereas the two other scales ("perception of bodily tension" and "adequate anger expression 
and assertiveness”) show moderate test-retest reliabilities. The total scale has a test-retest reliability of $R=.80$.

\section{Validity}

Convergent validity. The variances and correlations of the latent factors at measurement time 1 are depicted in Table 2. All factors show significant variation ranging from 0.28 (cognitive strategies and problem solving) to 1.41 (identification and use of social resources). All but one correlation are rather low showing that individuals differ in their use of coping strategies. Only “adequate anger expression and assertiveness” and “cognitive strategies and problem solving” correlated at $r=.65$ implying that individuals who cope cognitively with stress show higher scores on "adequate anger expression and assertiveness". The correlation analysis supports the idea of five related yet different aspects of stress coping behavior.

\section{Please insert Table 2 around here}

Criterion validity. Table 3 gives an overview on the multiple regression analyses conducted in order to investigate criterion validity. As expected higher ISBF total scores were significantly associated with lower levels of stress reactivity, irritation, anger out, vital exhaustion, and an emotion-oriented coping style, as well as with higher levels of perceived social support, anger control, and a task-oriented coping style (all $p$ 's $<.01$ ). Similarly, the hypothesized associations between ISBF subscales and criterion variables were confirmed (see $R^{2}$ change in Table 3). Specifically, higher scores on the scale "cognitive strategies and problem solving” were associated with lower stress reactivity, lower irritation, and lower scores in emotion-oriented coping, as well as with higher anger control and a higher taskoriented coping style (all $p^{\prime} s<.01$ ). Although not hypothesized, higher scores in the scale were also associated with lower vital exhaustion $(p<.01)$. As expected, higher scores in the 
scale "identification and use of social resources" were associated with higher levels of perceived social support ( $p<.01$ ), lower irritation, and interestingly, lower anger control (all $p$ 's $<.05)$. Higher levels in the scale "perception of bodily tension" were also associated with higher stress reactivity and higher exhaustion levels (all $p<.05$ ) as expected, but also with higher irritation $(p=.02)$. Higher levels in "adequate anger expression and assertiveness" were associated with lower anger-out and higher anger control (all $p<.05$ ). Finally, higher levels in the scale” relaxation abilities” were associated in the expected direction with lower stress reactivity and lower exhaustion (all $p<.05$ ). Higher "relaxation abilities” were also associated with lower irritation, and lower task-oriented coping (all $p<.05$ ).

Please insert Table 3 around here

\section{ENDOCRINE VALIDATION STUDY \\ Subjects' characteristics}

The total study sample consisted of 70 subjects whose characteristics are detailed in Table 4. In the workplace study, almost every second participant did smoke and almost every second women was using hormonal contraceptive medication.

Please insert Table 4 around here

\section{Stress management skills and cortisol at rest}

Laboratory study. At baseline, linear regression analysis revealed that higher ISBF total scores were associated with lower cortisol levels at rest, both without $(\beta=-.44, p=.008$, $\left.\mathrm{R}^{2}=.19\right)$ or with controlling for age, BMI, and MAP $\left(\beta=-.45, \mathrm{p}=.011\right.$, partial $\mathrm{R}^{2}=.19$, total $\mathrm{R}^{2}=.25$ ) (Fig. 1A). Post-hoc testing revealed a marginally significant association between higher scores in the scale "cognitive strategies and problem solving” and lower cortisol 
baseline levels $(\boldsymbol{\beta}=-.38, \mathrm{p}=.075)$ that disappeared after additional controlling for age, BMI, and MAP ( $\mathrm{p}=.19)$. None of the other scales were associated with cortisol at baseline either without (p’s>.18) or with controlling for the set of confounders (p’s>.26).

Workplace study. ISBF total score was not associated with cortisol baseline levels $(p=.14)$. However, when entering the full set of confounders the association became of borderline significance $(\boldsymbol{\beta}=-.32, \mathrm{p}=.09)$ with higher ISBF scores being associated with lower cortisol levels (Fig. 1B).

Combined analysis. In the combined analysis, higher ISBF total scores were associated with lower cortisol baseline levels with $((\beta=-.52, \mathrm{p}<.001)$ or without controlling for confounders $(\beta=-.44, p=.006)$.

\section{Stress management skills and cortisol stress reactivity}

Laboratory study. In the laboratory study, higher ISBF total scores were associated with lower cortisol levels before and after stress (main effect ISBF: $F(1 / 33)=10.4, p=.003$, partial $_{\text {eta }}^{2}=.24, \mathrm{f}=.56$ ) as well as with lower stress reactivity (interaction ISBF-by-stress: $\mathrm{F}(2.47 / 89.5)=4.7, \mathrm{p}=.006$, partial eta $\left.^{2}=.13, \mathrm{f}=.38\right)$. These associations did not significantly change when controlling for age, BMI, and MAP (main effect ISBF: $F(1 / 30)=7.1, p=.012$, partial eta $\left.^{2}=.19, \mathrm{f}=.49\right)$; interaction ISBF-by-stress: $\mathrm{F}(2.9 / 87.9)=3.3, \mathrm{p}=.026$, partial eta ${ }^{2}=.10$, $\mathrm{f}=.33)$ (Fig. 1A).

Workplace study. Similarly, in the workplace study higher ISBF total scores were also associated with lower cortisol stress reactivity (interaction ISBF-by-stress: $\mathrm{F}(2.4 / 71.2)=3.0, \mathrm{p}=.046$, partial eta $\left.^{2}=.09, \mathrm{f}=.32\right)$ and marginally associated with lower cortisol levels before and after stress (main effect ISBF: $\mathrm{F}(1 / 30)=4.0, \mathrm{p}=.054$, partial eta $\left.^{2}=.12, \mathrm{f}=.37\right)$. Gender, intake of hormonal contraceptives, and age were controlled. These associations became slightly stronger when additionally controlling for BMI and the number 
of cigarettes smoked per day (interaction ISBF-by-stress: $F(2.8 / 78.5)=3.8, \mathrm{p}=.016$, partial eta $^{2}=.12, \mathrm{f}=.37$; main effect ISBF: $\mathrm{F}(1 / 28)=5.3, \mathrm{p}=.029$, partial eta $\left.{ }^{2}=.16, \mathrm{f}=.44\right)($ Fig. $1 \mathrm{~B})$. Notably, gender did not interact with ISBF in predicting cortisol stress reactivity, neither without nor with controlling for confounders (p’s $>.80$ ).

Combined analysis. Results were confirmed in the combined analysis: higher ISBF total scores were independently associated with lower cortisol levels before and after stress (main effect ISBF: $F(1 / 62)=11.2, \mathrm{p}=.001$, partial eta $^{2}=.15, \mathrm{f}=.43$ ) as well as with lower cortisol stress reactivity (interaction ISBF-by-stress: $\mathrm{F}(2.91 / 180.6)=5.1, \mathrm{p}=.002$, partial eta $\left.^{2}=.08, \mathrm{f}=.29\right)$.

Results of subscale post-hoc tests are described and discussed in Supplemental Material 5.

Please insert Figure 1 around here

\section{DISCUSSION}

In this study we investigated psychometric properties of the ISBF, a short measure for combined assessment of perceived stress management skills across different non-clinical samples intended to represent the general population. We also investigated in two independent studies whether stress management skills as measured by ISBF would be associated with the reactivity of the HPA axis in reaction to a potent psychosocial stress test. Our results indicate both good psychometric properties of the instrument as well as independent associations between higher ISBF scores and lower cortisol stress reactivity.

With respect to the factor structure, the EFA as well as the CFA models showed that a five factor solution with the factors (1) cognitive strategies ("cognitive strategies and problem solving”), (2) social skills (“identification and use of social support”), (3) relaxation abilities, (4) anger regulation skills (“adequate anger expression and assertiveness”), and (5) the perception of bodily tension provides the best fit for the data. Notably, the final factor 
structure comprised only 14 items of the initial 17 items rendering the ISBF shorter. A closer look at the 3 items that had to be excluded suggests that their wording might be too ambivalent to clearly represent one single identified factor. For example, item 6 ("I can easily recognize situations that make me feel stressed or upset”) may not only include cognitive aspects (“recognize”) but also emotional facets (“feel stressed or upset”). The identified internal structure corresponds with our expectations: the items fit to their respective scales and the observed interscale-correlations indicate that the subscales are satisfyingly distinct and represent different facets (i.e., specific stress management skills) of the total construct. Estimating the multi-group CFA model revealed that the internal structure is stable with respect to factor loadings, intercepts, residual variances, and variances across samples. Therefore, we conclude that mean values (sum scores) can be calculated to represent the fivesubscales. Moreover, these scores can be compared across different samples in a general population since weak measurement invariance holds (Millsap, 1993). With respect to measurement invariance over time, weak measurement invariance was also identified in the longitudinal model. This suggests that ISBF scores can be compared over time (e.g., to examine the effect of stress management programs).

The calculated reliability coefficients in terms of scale and item reliabilities as well as test-retest reliabilities suggest adequate reliabilities of the ISBF scales. Notably, we tested test-retest reliability using two different intertest intervals, namely a shorter (7-14 days) and a longer (10 weeks) interval. Whereas we found perfect test-retest reliabilities at the latent level with the shorter interval, the longer interval showed satisfying reliabilities with moderate reliabilities for the scales "perception of bodily tension” and "adequate anger expression and assertiveness”. This suggests that the ISBF (and particularly the anger scale) is sensitive to changes over time (10 weeks interval) but does not artificially indicate changes when no changes take place (i.e., we cannot expect a change in stress management skills within 14 days, particularly if there is no intervention). 
With respect to validity, the data suggest convergent validity. The higher correlation between "cognitive strategies and problem solving” and "adequate anger expression and assertiveness" was to be expected given that successful anger regulation is most likely based on cognitive strategies. Indeed, current stress management trainings use cognitive strategies such as self-instructions to improve anger regulation skills (Siegrist, 1998; Wiegard, 2000). Similar to convergent validity, we found evidence for criterion validity as the individual ISBF scales and the ISBF total score significantly correlated with the validation instruments in the expected directions. Multiple regression analyses revealed that the set of ISBF scales have much more predictive power than the total ISBF score as shown by the amount of explained variance. Moreover, the data imply that the ISBF scales are substantially meaningful since every scale is related to at least one of the validation criteria. Furthermore, regression results suggest that specific criterion variables are attributable to corresponding stress management skills. For example, perceived social support is predicted by higher social skills (“identification and use of social resources”). Interestingly, this prediction becomes significantly better if the scale "identification and use of social resources" is added to a regression model including all other facets. Similarly, a person's tendency to show emotionoriented coping is virtually uniquely predicted by the person's cognitive strategy skills alone. The prediction of other criterion variables such as stress reactivity, irritation, task-oriented coping, and vital exhaustion comprise successful use of two or more stress management skills. Lower stress reactivity, irritation, and task-oriented coping relate to higher levels in cognitive strategies and relaxation abilities as well as lower bodily tension. Finally, lower vital exhaustion relates to almost all ISBF stress management skills except anger regulation. These findings seem plausible given that these three criterion variables represent complex constructs including both, psychological and physiological aspects and thus unlikely result from a single stress management skill. Indeed, stress reactivity, irritation, and vital exhaustion 
are best predicted by the combined use of all stress management skills (i.e., the set of subscales).

The findings of both endocrine studies analyzed separately as well as in a combined data set suggest that increased stress management skills in sum as measured by the ISBF total score may act as a buffer to attenuate physiological stress responses, as indicated by lower cortisol responses. Moreover, cortisol levels in general seem to be lower with increasing stress management skills as indicated by baseline levels and main effects. Our findings of significant associations between blunted cortisol reactivity and higher ISBF total scores are in line with previous research. They positively relate to psychological concepts that have been associated with lower cortisol stress reactivity, such as lower levels in psychological stress reactivity (as measured by the Stress-Reactivity Scale, (P. Schulz et al., 2005), higher perceived social support (Seeman and McEwen, 1996; Wirtz et al., 2009), and lower rumination as measured by the Irritation Scale (Zoccola et al., 2010). Also, relaxation techniques such as progressive muscle relaxation have been shown to acutely decrease activity of stress-response systems, thus possibly preparing for either active stress management or regeneration (Cruess et al., 2000; Pawlow and Jones, 2002, 2005).

What is the unique value of the ISBF and in how far does it differ from existing coping questionnaires such as the CISS (Endler and Parker, 1990) or other trait measures such as the validation instruments? In contrast to hitherto existing questionnaires the ISBF (and the MOCS respectively) assess something distinct, namely stress management skills supposed to allow for successful stress management and quantify their perceived mastery by a person. Notably, coping inventories such as the CISS do not assess coping skills but coping styles habitually used in stress situations independent of whether the respective coping style helps to successfully manage stress. Also, the same ISBF stress management skill may serve different coping styles or intentions and thus allows for a maximum of adaptation to a given situation. Associations between ISBF scales and other trait measures may result as consequences of the 
mastery of stress management skills (notably in interaction with the situation) which may lead to reduced stress experience, and consequently lower psychological and physiological stress reactivity or exhaustion. Similarly, specific stress management skills such as "identification and use of social support” are likely to enhance levels of perceived social support. Notably, although self-efficacy has been shown to be of importance for health and health promoting behaviors (Bandura, 1997, 2004), ISBF scores did not relate to self-efficacy as assessed in a subsample of our study ( $\mathrm{N}=93$, data not shown).

Our study has several strengths. For psychometric evaluation purposes we recruited three different independent non-clinical samples to represent the general population and calculated psychometric qualities of our questionnaire in all three samples simultaneously. Similarly, endocrine validation included investigation of two different independent nonclinical samples and analyses of physiological measures to examine the association between stress management skills and stress effects. Given that the same findings were observed across all respective samples indicates robustness of findings. Moreover, the factor structure of our questionnaire was confirmed by CFA which is a methodologically highly restrictive approach. A further strength of our study is that we investigated test-retest reliabilities by using two different test intervals, a shorter one and a longer one which allowed for a more detailed assessment of random fluctations and systematic effects on the measurement instrument. In addition, we tested criterion validity by assessing a broad range of psychological constructs that relate both to the ISBF in general, but also to at least one of the questionnaire's scales (i.e. stress management skills). Also, our psychometric assessment includes data from two different German-speaking countries, namely Switzerland and Germany, suggesting that the ISBF may be robust across different German speaking cultures and countries. Also, generalizability of our psychometric findings to the general population is high as we did not apply exclusion criteria other than age. Notably, we cannot rule out that some participants had high depression scores or experience in stress management training. 
Finally, for inducing stress responses, we used a well-validated standardized acute psychosocial stress task (Kirschbaum et al., 1993; Dickerson and Kemeny, 2004).

Several limitations must be considered in interpreting our findings. Our criterion validity was assessed based on data from self-administered questionnaires which per se limit objectivity of the used criterion variables. Moreover, the sensitivity of the questionnaire to change (e.g., stress management interventions or personal experiences) needs to be investigated. Furthermore, our ISBF psychometric property testing is restricted to the German version of the questionnaire and needs to be replicated in other languages and countries. The ISBF also needs to be normed for different age groups, men and women. Our calculations are based on samples intended to represent the general population - the usefulness of the instrument in extreme groups remains to be demonstrated. With respect to endocrine validation, it must first be noted that although we investigated two different independent samples, our results are restricted to a group of healthy, medication-free, non-smoking men and a group of well-educated young to middle-aged men and women. They cannot be generalized to other groups with less advantageous health conditions or socio-economic backgrounds. Second, we only measured salivary free cortisol as an indicator of HPA axis response to stress. It remains to be shown whether and how other stress-responsive physiological systems and endocrine parameters other than cortisol are related to stress management skills. Third, it is not the intention of the ISBF to allow for a complete assessment of all potentially existing stress management skills. Other methods not directly related to the cognitive-behavioral model of stress and stress-management have also shown to influence psychobiological stress reactivity (e.g. (Khalfa et al., 2003; Pace et al., 2009; Nedeljkovic et al., 2012)). Fourth, although additional controlling for trait anxiety and perceived chronic stress did not alter the association of lower cortisol stress reactivity with increasing stress management skills score in the laboratory study (data not shown), future studies in larger sample sizes are needed to confirm a unique value of the ISBF above and 
beyond established measures of perceived stress or trait anxiety. Finally, post-hoc test results of subscale associations with cortisol stress reactivity (see Supplemental Material 5) need to be interpreted with care since findings need to be replicated in larger studies with a higher power.

In sum, given its psychometric properties and its associations with both psychological and physiological stress indicators, the ISBF not only relates to subjective psychological, but also objective physiological stress reactivity measures. Thus, the ISBF may serve as a promising short, reliable, and valid questionnaire to assess the extent of a person's existing stress management skills and its potential improvement by interventions. We feel that the ISBF can be regarded both as a process measure as it assesses processes through which stress management operates but also as an outcome measure as it quantifies mastery of these processes and as the ISBF is stable and relates to indicators of successful stress management (e.g. lower cortisol stress reactivity, lower exhaustion, lower subjective stress reactivity). Future research is needed to elucidate further psychometric properties such as norms or clinical implications and to investigate the mechanisms underlying lower cortisol reactivity with increasing stress management abilities (e.g. to clarify whether stress susceptibility and thus stress reactivity in general is lower with increasing stress management skills or whether persons with higher stress management skills use specific strategies in the stress situation).

\section{Acknowledgements}

We thank Claudia Bussinger-Koller, Maja Hunziker-Bircher, Estherina DiStefano, Alexandra Laerbusch, Frank Stein, Rebecca Meister and Angela Arpagaus for their help in data acquisition of subsamples. Work was supported by the Swiss National Science Foundation (Grant PP00P1_128565/1, to PHW) and Chocosuisse (Association of Swiss Chocolate Manufacturers, Grant 2009), to PHW). 
Financial Disclosures: none 


\section{REFERENCES}

Antoni, M.H., Lechner, S.C., Kazi, A., Wimberly, S.R., Sifre, T., Urcuyo, K.R., Phillips, K., Gluck, S., Carver, C.S., 2006. How stress management improves quality of life after treatment for breast cancer. J Consult Clin Psychol. 74, 1143-1152.

Appels, A., 1997. Exhausted subjects, exhausted systems. Acta Physiol Scand Suppl. 640, 153-154.

Babyak, M.A., 2004. What you see may not be what you get: a brief, nontechnical introduction to overfitting in regression-type models. Psychosom. Med. 66, 411-421.

Bandura, A. (1997). Perceived self-efficacy in health-promoting behavior. In A. Bandura (Ed.), Self-efficacy - the exercise of control (Vol. W.H. Freeman and Company, pp. 279-312). New York.

Bandura, A., 2004. Swimming against the mainstream: the early years from chilly tributary to transformative mainstream. Behav Res Ther. 42, 613-630.

Brotman, D.J., Golden, S.H., Wittstein, I.S., 2007. The cardiovascular toll of stress. Lancet. 370, 1089-1100.

Carver, C.S. (2005). Measure of Current Status. Retrieved July, 2004, from Department of Psychology, University of Miami Web site: http:// www.psy.miami.edu/faculty/ccarver/sclMOCS.html.

Chida, Y., Hamer, M., 2008. Chronic psychosocial factors and acute physiological responses to laboratory-induced stress in healthy populations: a quantitative review of 30 years of investigations. Psychol Bull. 134, 829-885.

Chida, Y., Steptoe, A., 2010. Greater cardiovascular responses to laboratory mental stress are associated with poor subsequent cardiovascular risk status: a meta-analysis of prospective evidence. Hypertension. 55, 1026-1032.

Christenfeld, N., Gerin, W., 2000. Social support and cardiovascular reactivity. Biomed Pharmacother. 54, 251-257. 
Cruess, D.G., Antoni, M.H., Kumar, M., Schneiderman, N., 2000. Reductions in salivary cortisol are associated with mood improvement during relaxation training among HIV-seropositive men. J Behav Med. 23, 107-122.

Dickerson, S.S., Kemeny, M.E., 2004. Acute stressors and cortisol responses: a theoretical integration and synthesis of laboratory research. PsyB. 130, 355-391.

Endler, N.S., Parker, J.D.A., 1990. Coping Inventory for Stressful Situations (CISS): Manual. Multi-Health Systems, Toronto,

Gaab, J., Blattler, N., Menzi, T., Pabst, B., Stoyer, S., Ehlert, U., 2003. Randomized controlled evaluation of the effects of cognitive-behavioral stress management on cortisol responses to acute stress in healthy subjects. Psychoneuroendocrinology. 28, 767-779.

Gaab, J., Rohleder, N., Nater, U.M., Ehlert, U., 2005. Psychological determinants of the cortisol stress response: the role of anticipatory cognitive appraisal. Psychoneuroendocrinology. 30, 599-610.

Habra, M.E., Linden, W., Anderson, J.C., Weinberg, J., 2003. Type D personality is related to cardiovascular and neuroendocrine reactivity to acute stress. J Psychosom Res. 55, 235-245.

Hammerfald, K., Eberle, C., Grau, M., Kinsperger, A., Zimmermann, A., Ehlert, U., Gaab, J., 2005. Persistent effects of cognitive-behavioral stress management on cortisol responses to acute stress in healthy subjects-A randomized controlled trial. Psychoneuroendocrinology.

Heinrichs, M., Baumgartner, T., Kirschbaum, C., Ehlert, U., 2003. Social support and oxytocin interact to suppress cortisol and subjective responses to psychosocial stress. Biol Psychiatry. 54, 1389-1398.

Hinsch, R., Pfingsten, U., 2007. Das Gruppentraining sozialer Kompetenzen (GSK). Grundlagen, Durchführung, Materialien. PVU, Weinheim, 
Holmes, S.D., Krantz, D.S., Rogers, H., Gottdiener, J., Contrada, R.J., 2006. Mental stress and coronary artery disease: a multidisciplinary guide. Prog Cardiovasc Dis. 49, 106122.

Kälin, W. (1995). German 24-item short form of the Coping Inventory for Stressful Situations (CISS) by N.S. Endler and J.D.A. Parker. Based on the translation by N. Semmer, F. Tschan, and V. Schade (unpublished questionnaire)]. . University of Bern, Bern.

Kaluza, G., 1996. Gelassen und sicher im Stress. Springer, Berlin Heidelberg,

Khalfa, S., Bella, S.D., Roy, M., Peretz, I., Lupien, S.J., 2003. Effects of relaxing music on salivary cortisol level after psychological stress. Ann N Y Acad Sci. 999, 374-376.

Kirschbaum, C., Kudielka, B.M., Gaab, J., Schommer, N.C., Hellhammer, D.H., 1999. Impact of gender, menstrual cycle phase, and oral contraceptives on the activity of the hypothalamus-pituitary-adrenal axis. Psychosom. Med. 61, 154-162.

Kirschbaum, C., Pirke, K.M., Hellhammer, D.H., 1993. The 'Trier Social Stress Test'--a tool for investigating psychobiological stress responses in a laboratory setting. Neuropsychobiology. 28, 76-81.

Kopp, M.S., Falger, P.R., Appels, A., Szedmak, S. (Cartographer). (1998). Depressive symptomatology and vital exhaustion are differentially related to behavioral risk factors for coronary artery disease.

Kudielka, B.M., Buske-Kirschbaum, A., Hellhammer, D.H., Kirschbaum, C., 2004a. HPA axis responses to laboratory psychosocial stress in healthy elderly adults, younger adults, and children: impact of age and gender. Psychoneuroendocrinology. 29, 83-98.

Kudielka, B.M., von Kanel, R., Gander, M.L., Fischer, J.E., 2004b. The interrelationship of psychosocial risk factors for coronary artery disease in a working population: do we measure distinct or overlapping psychological concepts? Behav Med. 30, 35-43.

Lazarus, R.S., Folkman, S., 1984. Stress, appraisal, and coping., Springer Publishing Company, New York, 
Lepore, S.J., 1998. Problems and prospects for the social support-reactivity hypothesis. Ann Behav Med. 20, 257-269.

Meichenbaum, D., 1985. Stress Inocuation Training. Pergamon Press, New York, Meichenbaum, D., 1991. Intervention bei Stress - Anwendung und Wirkung des Stressimpfungstrainings. L. Schattenburg, Trans., Hans Huber, Bern,

Meredith, W., 1993. Measurement invariance, factor analysis and factorial invariance. Psychometrika. 525-543.

Millsap, R.E., 1993. Measurement invariance, factor analysis and factorial invariance. Psychometrika. 58, 525-543.

Mohr, G., Müller, A., Rigotti, T., 2005. Standardisation data of the Irritation Scale. Two dimensions of mental strain. Diagnostica. 51, 12-20.

Müller, A., Mohr, G., Rigotti, T., 2004. Differential Aspects of Psychological Strain With Respect to Goal Orientation: The Factor-Structure of The Irritation Scale. Zeitschrift für Differentielle und Diagnostische Psychologie. 25, 213-225.

Müller, C., Bongard, S., Heiligtag, U., Hodapp, V., 2001. Das State-Trait-ÄrgerausdrucksInventar (STAXI) in der klinischen Anwendung: Reliabilität und faktorielle Validität. Zeitschrift für Klinische Psychologie und Psychotherapie. 30, 172-181.

Muthén, L.K., Muthén, B.O., 1998-2010. Mplus user's guide. 5 ed., Muthén \& Muthén, Los Angeles, CA,

Nausheen, B., Gidron, Y., Gregg, A., Tissarchondou, H.S., Peveler, R., 2007. Loneliness, social support and cardiovascular reactivity to laboratory stress. Stress. 10, 37-44.

Nedeljkovic, M., Ausfeld-Hafter, B., Streitberger, K., Seiler, R., Wirtz, P.H., 2012. Taiji practice attenuates psychobiological stress reactivity - A randomized controlled trial in healthy subjects. Psychoneuroendocrinology. 37, 1171-1180.

Pace, T.W., Negi, L.T., Adame, D.D., Cole, S.P., Sivilli, T.I., Brown, T.D., Issa, M.J., Raison, C.L., 2009. Effect of compassion meditation on neuroendocrine, innate 
immune and behavioral responses to psychosocial stress. Psychoneuroendocrinology. 34, 87-98.

Pawlow, L.A., Jones, G.E., 2002. The impact of abbreviated progressive muscle relaxation on salivary cortisol. Biol Psychol. 60, 1-16.

Pawlow, L.A., Jones, G.E., 2005. The impact of abbreviated progressive muscle relaxation on salivary cortisol and salivary immunoglobulin A (sIgA). Appl Psychophysiol Biofeedback. 30, 375-387.

Penedo, F.J., Dahn, J.R., Gonzalez, J.S., Molton, I., Carver, C.S., Antoni, M.H., Roos, B.A., Schneiderman, N., 2003. Perceived stress management skill mediates the relationship between optimism and positive mood following radical prostatectomy. Health Psychol. 22, 220-222.

Penedo, F.J., Dahn, J.R., Molton, I., Gonzalez, J.S., Kinsinger, D., Roos, B.A., Carver, C.S., Schneiderman, N., Antoni, M.H., 2004. Cognitive-behavioral stress management improves stress-management skills and quality of life in men recovering from treatment of prostate carcinoma. Cancer. 100, 192-200.

Penedo, F.J., Molton, I., Dahn, J.R., Shen, B.J., Kinsinger, D., Traeger, L., Siegel, S., Schneiderman, N., Antoni, M., 2006. A randomized clinical trial of group-based cognitive-behavioral stress management in localized prostate cancer: development of stress management skills improves quality of life and benefit finding. Ann Behav Med. 31, 261-270.

Reschke, K., Schröder, H., 2000. Optimistisch den Stress meistern. Deutsche Gesellschaft für Verhaltenstherapie, Tübingen,

Schermelleh-Engel, K., Moosbrugger, H., Müller, H., 2003. Evaluating the fit of structural equation models: Test of significance and descriptive goodness-of-fit measures. Methods of Psychological Research - Online. 8, 23-74. 
Schmidt, R.F., Thews, G. (1987). Functions of the vascular system (Funktionen des Gefäßsystems). In R. F. Schmidt, G. Thews (Eds.), Human Physiology (Physiologie des Menschen) (Vol. 21, pp. 518-519). Berlin Heidelberg New York: Springer.

Schulz, P., Jansen, L.J., Schlotz, W., 2005. Stressreaktivität: Theoretisches Konzept und Messung. Diagnostica. 51, 124-133.

Schulz, U., Schwarzer, R., 2003. Social support and coping with illness: The Berlin Social Support Scales (BSSS). Diagnostica. 49, 73-82.

Schwenkmezger, P., Hodapp, V., Spielberger, C.D., 1992. Das State-Trait-ÄrgerausdrucksInventar (STAXI). Huber, Bern,

Seeman, T.E., McEwen, B.S., 1996. Impact of social environment characteristics on neuroendocrine regulation. Psychosom Med. 58, 459-471.

Siegrist, K., Silberhorn, T., 1998. Stressabbau in Organisationen - ein Manual zum Stressmanagement. 1 ed., LIT Verlag, Münster,

Uchino, B.N., 2006. Social support and health: a review of physiological processes potentially underlying links to disease outcomes. J Behav Med. 29, 377-387.

Uchino, B.N., Cacioppo, J.T., Kiecolt-Glaser, J.K., 1996. The relationship between social support and physiological processes: a review with emphasis on underlying mechanisms and implications for health. Psychol Bull. 119, 488-531.

Wagner-Link, A., 2001. Verhaltenstraining zur Stressbewältigung - Arbeitsbuch für Therapeuten und Trainer. Pfeiffer bei Klett-Cotta, Stuttgart,

Wiegard, U., Tauscher, N., Inhester, M.L., Puls, W., Wienold, H. (2000). Gelassen bei der Arbeit (Forschungsprojekt "Gesundheitsförderung in der Arbeitswelt" No. 1/2000). Münster: Westfälische Wilhelms-Universität Münster, Institut für Soziologie, Forschungsgruppe "Arbeit und Gesundheit". 
Wirtz, P.H., Redwine, L.S., Ehlert, U., von Kanel, R., 2009. Independent association between lower level of social support and higher coagulation activity before and after acute psychosocial stress. Psychosom Med. 71, 30-37.

Wirtz, P.H., von Kanel, R., Mohiyeddini, C., Emini, L., Ruedisueli, K., Groessbauer, S., Ehlert, U., 2006. Low social support and poor emotional regulation are associated with increased stress hormone reactivity to mental stress in systemic hypertension. $\mathrm{J}$ Clin Endocrinol Metab. 91, 3857-3865.

Wirtz, P.H., Von Kanel, R., Schnorpfeil, P., Ehlert, U., Frey, K., Fischer, J.E., 2003. Reduced Glucocorticoid Sensitivity of Monocyte Interleukin-6 Production in Male Industrial Employees who are Vitally Exhausted. Psychosom Med. 65, 672-678.

Zoccola, P.M., Quas, J.A., Yim, I.S., 2010. Salivary cortisol responses to a psychosocial laboratory stressor and later verbal recall of the stressor: The role of trait and state rumination. Stress. 13, 435-443. 


\section{Legend to Figure 1}

Values are means \pm SEM. We calculated general linear models with repeated measures of the stress hormone cortisol as dependent variables and stress management skills as measured by ISBF total scores as continuous independent variable while controlling for the full sets of confounders. For illustrative purposes we depict two groups of subjects with lower (quartiles 1 and 2) and with higher ISBF total scores (quartiles 3 and 4). Higher stress management skills were associated with lower cortisol stress reactivity in the laboratory study $(p=0.026, n=35$, Figure $1 A)$ and in the workplace study $(p=0.016, n=35$, Figure $1 B)$ while controlling for the full sets of à-priori defined potential confounders. 
Figure 1. Cortisol stress reactivity to psychosocial stress (TSST) in subjects with lower and higher stress management skills as measured by ISBF total scores.

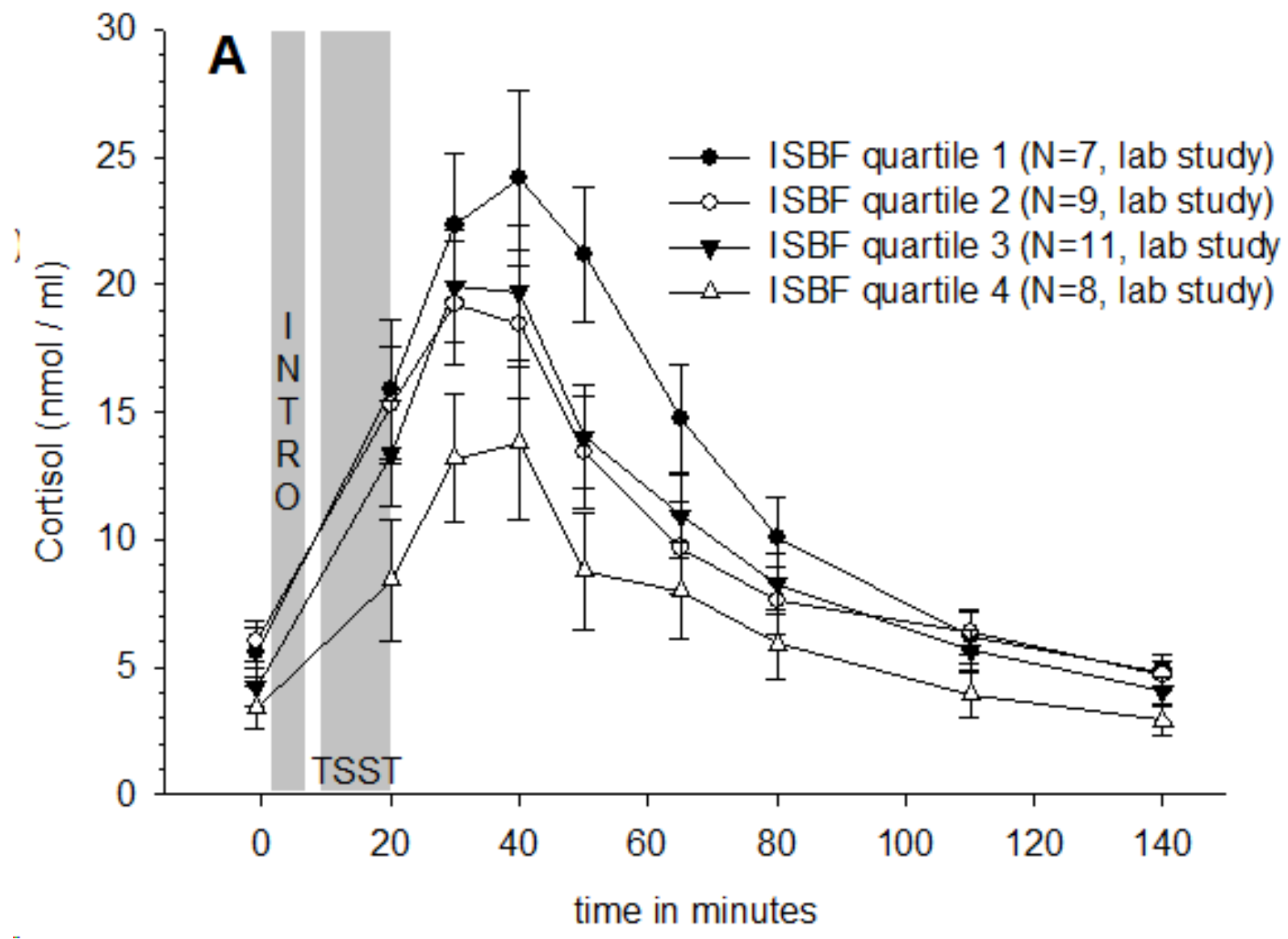




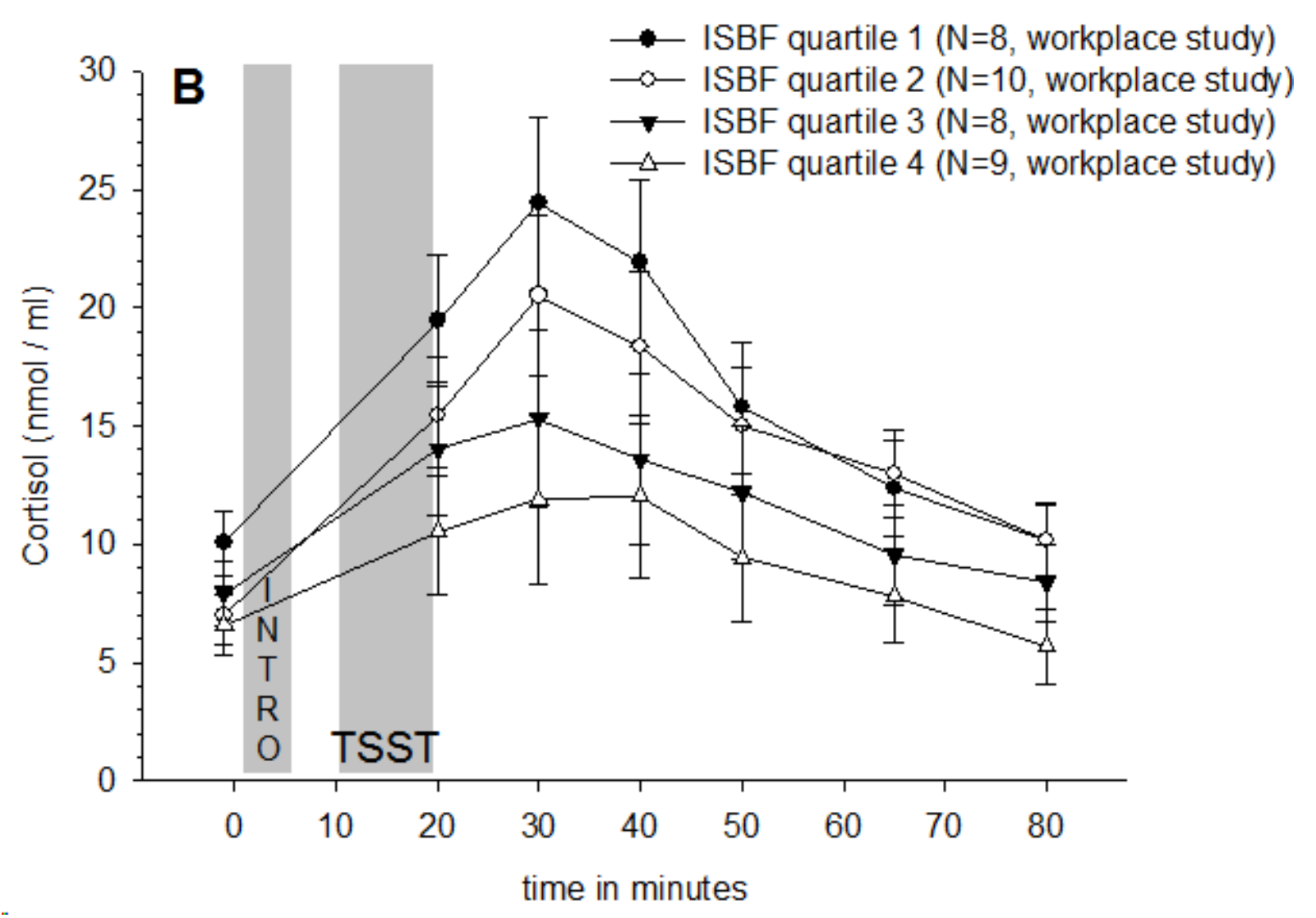


Table 1. Scales and items of the ISBF, factor loadings, and reliability coefficients of scales and items

\begin{tabular}{cccc}
\hline Scale & Item & Item wording & Feliability \\
& $\mathrm{nr}$ & English (German) & coefficients*
\end{tabular}

\section{Total}

Scale

CogProb

I can easily stop and re-examine my thoughts to gain a new

perspective (Ich kann meine Gedanken leicht stoppen und

überprüfen, um zu neuen Perspektiven zu gelangen)

5 It's easy for me to decide how to cope with whatever problems arise

(Es fällt mir leicht zu entscheiden, wie ich mit neu aufgetauchten

Probleme umgehen kann)

8 When problems arise I know how to cope with them (Wenn Probleme

auftauchen, weiss ich, wie ich sie angehe)

15 I am confident about being able to choose the best coping responses

for hard situations (Ich vertraue darauf, dass ich in schwierigen

Situationen in der Lage bin, die besten Bewältigungsstrategien zu 
wählen)

16 I can come up with emotionally balanced thoughts even during

negative times (Auch in belasteten Zeiten kann ich emotional

ausgeglichene Gedanken aufkommen lassen)

\begin{tabular}{|c|c|c|c|c|}
\hline \multirow[t]{3}{*}{ SocRes } & & & & .82 \\
\hline & 10 & $\begin{array}{l}\text { It’s easy for me to go to people in my life for help or support when I } \\
\text { need it (Es fällt mir leicht, Menschen aus meinem Umfeld um } \\
\text { Unterstützung zu bitten, wenn ich Unterstützung brauche) }\end{array}$ & .91 & .82 \\
\hline & 17 & $\begin{array}{l}\text { I can ask people in my life for support or assistance whenever I need } \\
\text { it (Wann immer es nötig ist, kann ich Menschen aus meinem Umfeld } \\
\text { um Unterstützung oder Beistand bitten) }\end{array}$ & .76 & .58 \\
\hline \multirow[t]{3}{*}{ RelaxAb } & & & & .67 \\
\hline & 1 & $\begin{array}{l}\text { I am able to use muscle relaxation techniques to reduce any tension I } \\
\text { experience (Ich bin in der Lage, Muskelentspannungstechniken } \\
\text { anzuwenden, um wahrgenommene Anspannung zu reduzieren) }\end{array}$ & .71 & .51 \\
\hline & 13 & $\begin{array}{l}\text { I am able to use mental imagery to reduce any tension I experience } \\
\text { (Ich kann mich mentaler Bilder bedienen, um meine Anspannung zu } \\
\text { reduzieren) }\end{array}$ & .65 & .43 \\
\hline
\end{tabular}


(Wenn ich ärgerlich werde, kann ich kann meinen Ärger offen

$$
\text { zeigen, ohne zu übertreiben) }
$$

12 I can stand up for my rights without violating the rights of others (Ich

kann für meine Rechte einstehen, ohne damit die Rechte anderer zu

$$
\text { verletzen) }
$$

14 I can express my anger in a balanced and reasonable manner (Ich

kann meinen Ärger in vernünftiger und ausgewogener Art und Weise

ausdrücken)

\section{PBodTens}

(Wenn sich Verspannungen im meinem Körper aufbauen, dann merke ich das sofort)

bemerke sofort, wenn mein Körper beginnt, sich zu verspannen) 
(Ich kann Situationen, die mich unter Stress setzen oder die mich aus der Ruhe bringen, gut erkennen)

11 I am aware of the stream of thoughts that pass through my mind as events occur (Ich bin mir der Gedankenflut bewusst, die mir bei auftauchenden Ereignissen durch den Kopf strömt)

CogProb, scale “cognitive strategies and problem solving”; SocRes, scale “ identification and use of social resources”; RelaxAb, scale

“relaxation abilities”; AngExAs, scale “adequate anger expression and assertiveness”; PBodTens, scale “perception of bodily tension”;

Excluded, items 3, 6, and 11 of the initial questionnaire that were excluded in the CFA models; factor loadings, standardized factor loadings of the 5-factor multigroup CFA-model, all factor loadings are significant ( $t$-values $>2)$; ${ }^{*}$, scale reliability (internal consistency of the scale $=$ Cronbachs's $\alpha$ ) and item reliability (variance of the items explained by the latent factor). 
Table 2. Variances and correlations of the 5-factor multigroup CFA-model (convergent validity)

\begin{tabular}{|c|c|c|c|c|c|c|c|}
\hline & CogProb & SocRes & RelaxAb & AngExAs & PBodTens & $\begin{array}{l}\text { Retest-reliability }^{1} \\
\text { (7-14 days, } \\
\text { samples } 1 \text { and 2) }\end{array}$ & $\begin{array}{l}\text { Retest-reliability }^{1} \\
\text { (10 weeks, sample 3) }\end{array}$ \\
\hline CogProb & 0.28 & & & & & 1.0 & .80 \\
\hline SocRes & .32 & 1.41 & & & & 1.0 & .83 \\
\hline RelaxAb & .35 & .23 & 0.47 & & & 1.0 & .76 \\
\hline AngExAs & .65 & .34 & .32 & 0.41 & & 1.0 & .52 \\
\hline PBodTens & .09 & .14 & .35 & .21 & 0.75 & 1.0 & .69 \\
\hline
\end{tabular}

Notes. Correlations are depicted in the lower triangular, Variances are printed in italics on the main diagonal. Values in bold type represent coefficients with associated $t$-values $>2.00 .^{1}$ : Test-retest reliabilities are estimated in the longitudinal multigroup CFA-model. 
Table 3. Results of the multiple regression analyses (criterion validity)

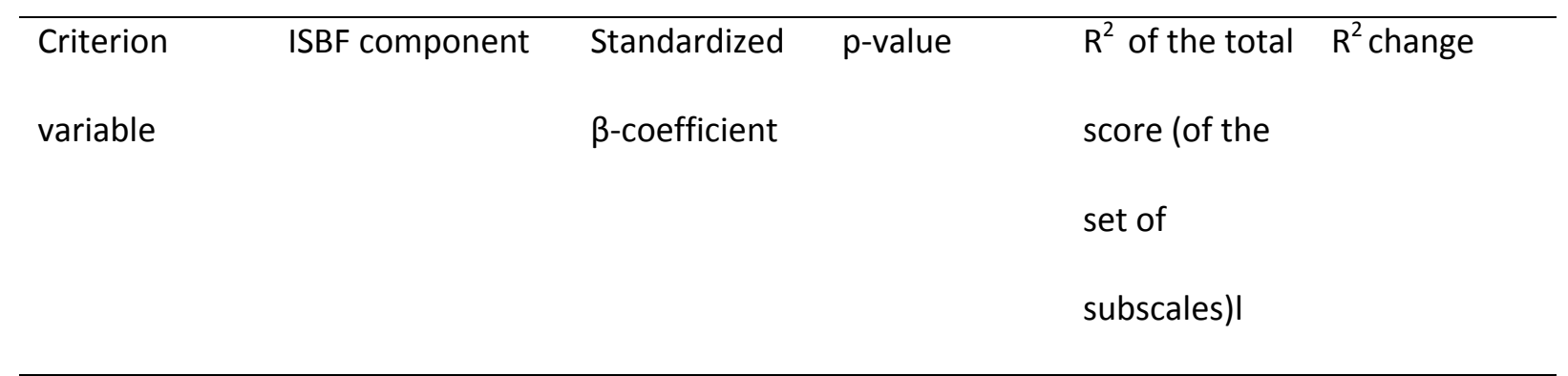

\begin{tabular}{|c|c|c|c|c|c|}
\hline \multirow{2}{*}{\multicolumn{6}{|c|}{$\begin{array}{l}\text { Stress } \\
\text { reactivity }\end{array}$}} \\
\hline & & & & & \\
\hline & Total score (-) & -.48 & .00 & $.23(.43)$ & \\
\hline & CogProb (-) & -.58 & .00 & & .23 \\
\hline & SocRes & -.04 & .44 & & \\
\hline & PBodTens (+) & .21 & .04 & & .04 \\
\hline & AngExAs & -.04 & .49 & & \\
\hline & RelaxAb (-) & -.11 & .00 & & .01 \\
\hline \multicolumn{6}{|c|}{ Irritation } \\
\hline & Total score (-) & -.50 & .00 & $.25(.34)$ & \\
\hline & CogProb (-) & -.45 & .00 & & .14 \\
\hline & SocRes & -.11 & .03 & & \\
\hline & PBodTens & .12 & .02 & & \\
\hline & AngExAs & -.06 & .29 & & \\
\hline & RelaxAb & -.13 & .02 & & \\
\hline \multicolumn{6}{|c|}{ Social support } \\
\hline & Total score(+) & .32 & .00 & $.10(.15)$ & \\
\hline & CogProb & .11 & .10 & & \\
\hline & SocRes (+) & .32 & .00 & & .09 \\
\hline & PBodTens & .07 & .54 & & \\
\hline
\end{tabular}




$\begin{array}{lll}\text { AngExAs } & -.04 & .55\end{array}$

$\begin{array}{lll}\text { RelaxAb } & .04 & .23\end{array}$

\begin{tabular}{|c|c|c|c|c|c|}
\hline Anger-out & & & & & \\
\hline & Total score (-) & -.18 & .00 & $.03(.05)$ & \\
\hline & CogProb & -.10 & .16 & & \\
\hline & SocRes & .01 & .84 & & \\
\hline & PBodTens & -.08 & .52 & & \\
\hline & $\operatorname{AngExAs}(-)$ & -.14 & .04 & & .01 \\
\hline & RelaxAb & .04 & .21 & & \\
\hline Anger cont & & & & & \\
\hline & Total score & .35 & .00 & $.12(.19)$ & \\
\hline & CogProb & .32 & .00 & & .07 \\
\hline & SocRes & -.12 & .04 & & \\
\hline & PBodTens & -.00 & .96 & & \\
\hline & AngExAs & .17 & .01 & & .02 \\
\hline & RelaxAb & .09 & .17 & & \\
\hline
\end{tabular}

Vital

exhaustion

$\begin{array}{lccc}\text { Total score(-) } & -.39 & .00 & .16(.21) \\ \text { CogProb } & -.31 & .03 & \\ \text { SocRes } & -.10 & .08 & .01 \\ \text { PBodTens (+) } & .13 & .00 & \\ \text { AngExAs } & -.02 & .74 & .03 \\ \text { RelaxAb (-) } & -.20 & .03 & \end{array}$

Task-oriented

coping 


$\begin{array}{llll}\text { Total score }(+) & .48 & .00 & .23(.28) \\ \text { CogProb (+) } & .39 & .00 & .10 \\ \text { SocRes } & .03 & .90 & \\ \text { PBodTens } & -.03 & .63 \\ \text { AngExAs } & .10 & .09 \\ \text { RelaxAb } & .15 & .01\end{array}$

Emotion-

oriented

coping

$\begin{array}{llll}\text { Total score (-) } & -.48 & .00 & .23(.34) \\ \text { CogProb (-) } & -.53 & .00 & .19 \\ \text { SocRes } & -.03 & .56 & \\ \text { PBodTens } & .08 & .23 \\ \text { AngExAs } & -.04 & .48 \\ \text { RelaxAb } & -.07 & .14\end{array}$

$\mathrm{R}^{2}$, explained variance; $\mathrm{R}^{2}$ change: increase in determination coefficient if the corresponding variable is added to the model with all other variables as predictors;

CogProb, scale “cognitive strategies and problem solving”; SocRes, scale “ identification and use of social resources”; RelaxAb, scale "relaxation abilities”; AngExAs, scale “adequate anger expression and assertiveness”; PBodTens, scale "perception of bodily tension”; ISBF components in italics were a-priori supposed to correlate with the respective criterion with the expected direction of the association in brackets. 
Table 4. Characteristics of the $\mathbf{7 0}$ study subjects in the endocrine validation study

\begin{tabular}{|c|c|c|}
\hline & Laboratory study $(\mathrm{N}=35)$ & Workplace study ( $\mathrm{N}=35)$ \\
\hline & Mean \pm SEM (range) & Mean \pm SEM (range) \\
\hline Age [years] & $38.0 \pm 1.6(20-62)$ & $32.9 \pm 1.2(20-45)$ \\
\hline Body mass index $\left[\mathrm{kg} / \mathrm{m}^{2}\right]$ & $25.5 \pm 0.8(18.7-39.8)$ & $24.1 \pm 0.7(17.1-35.2)$ \\
\hline Gender [N men/ N women] & $35 / 0$ & $16 / 19$ \\
\hline Hormonal contraceptives [N] & 0 & 9 \\
\hline Mean arterial pressure [mmHg] & $92.1 \pm 1.7(75.8-117.3)$ & - \\
\hline Smoker [N, cig/day] & 0 & $16,6.8 \pm 1.4(0-30)$ \\
\hline Full- or part-time job [\% (N)] & $80(28)$ & $100(35)$ \\
\hline \multicolumn{3}{|l|}{ Stress management skills } \\
\hline \multicolumn{3}{|l|}{ (ISBF scores) } \\
\hline ISBF total score & $3.3 \pm 0.8(2.57-4.36)$ & $3.2 \pm 0.9(2.07-3.93)$ \\
\hline CogProb & $3.5 \pm 0.9(2.20-4.40)$ & $3.2 \pm 0.8(2.40-4.00)$ \\
\hline SocRes & $3.4 \pm 0.1(2.00-5.00)$ & $3.3 \pm 0.2(1.00-5.00)$ \\
\hline PBodTens & $3.2 \pm 0.2(1.00-5.00)$ & $3.6 \pm 0.2(1.00-5.00)$ \\
\hline AngExAs & $3.5 \pm 0.9(2.00-4.67)$ & $3.4 \pm 0.1(1.67-4.67)$ \\
\hline RelaxAb & $2.6 \pm 0.2(1.00-4.50)$ & $2.5 \pm 0.2(1.00-4.50)$ \\
\hline \multicolumn{3}{|c|}{ N, valid cases; cig/day, number of smoked cigarettes per day; Stress Managament Skills } \\
\hline \multicolumn{3}{|c|}{ Inventory; CogProb, ISBF scale “cognitive strategies and problem solving”; SocRes, ISBF } \\
\hline \multicolumn{3}{|c|}{ scale “ identification and use of social resources”; RelaxAb, ISBF scale "relaxation } \\
\hline \multicolumn{3}{|c|}{ abilities”; AngExAs, ISBF scale “adequate anger expression and assertiveness”; PBodTens, } \\
\hline
\end{tabular}

